\title{
Real-world outcomes following 12 months of intravitreal aflibercept monotherapy in patients with diabetic macular edema in France: results from the APOLLON study
}

\author{
Jean-François Korobelnik ${ }^{1,2}$ - Vincent Daien ${ }^{3}$ - Céline Faure ${ }^{4} \cdot$ Ramin Tadayoni $^{5}$ - Audrey Giocanti-Auregan ${ }^{6}$. \\ Corinne Dot $^{7} \cdot$ Laurent Kodjikian $^{8} \cdot$ Pascale Massin $^{9}$
}

Received: 5 November 2019 / Revised: 20 December 2019 / Accepted: 24 December 2019 / Published online: 2 January 2020

(C) The Author(s) 2019

\begin{abstract}
Purpose To report the effectiveness of intravitreal aflibercept (IVT-AFL) treatment for diabetic macular edema (DME) in French clinical practice.

Methods APOLLON (NCT02924311) was a prospective, observational cohort study of patients with DME. Effectiveness was evaluated by change from baseline in best-corrected visual acuity (BCVA) at 12 months in treatment-naïve patients (i.e., had not received any anti-vascular endothelial growth factor [anti-VEGF] agent, laser, or steroid at IVT-AFL treatment start) and previously treated patients (i.e., previously treated with anti-VEGF agents other than IVT-AFL, laser, or steroids at IVT-AFL treatment start). Secondary endpoints included change in central retinal thickness (CRT) over 12 months, frequency of injections, and proportion of patients with safety events.

Results Of the 147 patients followed for at least 12 months and included in the effectiveness analysis, 52.4\% $(n=77)$ were treatment-naïve and $47.6 \%(n=70)$ were previously treated. Mean (standard deviation [SD]) BCVA score at baseline was 62.7 (14.3) Early Treatment Diabetic Retinopathy Study (ETDRS) letters in treatment-naïve patients and 60.0 (13.7) ETDRS letters in previously treated patients. At month 12, mean (SD) change in BCVA was + 7.8 (12.3) letters in treatment-naïve patients and + 5.0 (11.3) letters in previously treated patients. Mean CRT decreased in both patient cohorts. The mean (SD) number of IVT-AFL injections at month 12 was 7.6 (2.5) for treatment-naïve patients and 7.6 (2.3) for previously treated patients. Of 388 patients included in the safety analysis, ocular treatment-emergent adverse events occurred in $54.1 \%(n=210)$ of patients.

Conclusion IVT-AFL treatment was associated with improvements in functional and anatomic outcomes in both treatment-naïve and previously treated patients with DME in France.
\end{abstract}

Keywords Aflibercept $\cdot$ Diabetic macular edema $\cdot$ Anti-VEGF $\cdot$ Diabetic retinopathy

\section{Introduction}

Diabetic macular edema (DME) is a complication of diabetic retinopathy and manifests as retinal thickening from

Jean-François Korobelnik

jean-francois.korobelnik@chu-bordeaux.fr

Service d'ophtalmologie, CHU de Bordeaux, Bordeaux, France

2 Bordeaux Population Health Research Centre, Team LEHA, Université de Bordeaux, INSERM, UMR 1219,

F-33000 Bordeaux, France

3 Hôpital Gui De Chauliac, INSERM, Université de Montpellier, Montpellier, France the accumulation of intraretinal fluid (IRF) caused by failure of the blood-retinal barrier [1]. DME is the leading cause of visual impairment in patients with diabetes [2] and its rate is expected to rise in the next decade due to

4 Clinique Saint-Martin, Ramsay Générale de Santé, Caen, France

5 Hôpital Lariboisière, AP-HP, Université Paris 7 - Sorbonne Paris Cité, Paris Hôpital, Paris, France

6 Avicenne, AP-HP, Université Paris 13, DHU Vision et Handicaps, Bobigny, France

7 HIA Desgenettes, Lyon, France

8 Centre Hospitalier de la Cr Rousse, Université de Lyon, Lyon, France

9 CUDC, Hôpital Lariboisière, Paris, France 
the substantial increase in worldwide incidence of diabetes [3]. The Wisconsin Epidemiologic Study of Diabetic Retinopathy reported that the incidence of DME in patients with type 1 or type 2 diabetes doubled within 5-6 years of disease diagnosis [4].

Anti-vascular endothelial growth factor (anti-VEGF) agents, such as intravitreal aflibercept (IVT-AFL) and ranibizumab, are recommended as first-line therapy for DME [1]; their use is based on the observation that VEGF levels are increased in the retina of patients with retinopathies and that VEGF acts as an important mediator of the bloodretinal barrier breakdown $[5,6]$. Results from the phase 3 VISTA-DME and VIVID-DME studies showed that IVTAFL treatment was associated with statistically significant improvements in visual outcomes compared with laser [7]. The efficacy demonstrated in clinical trials does not always reflect the effectiveness achieved in a real-world setting due to selection biases in the former and poor adherence in the latter. Therefore, real-world studies are useful in showing the effectiveness of anti-VEGF agents in DME management in current clinical settings.

APOLLON was a prospective, observational study that evaluated the effectiveness of IVT-AFL treatment in patients with DME in French clinical practice over a period of 24 months. Here, we report functional and anatomic outcomes and safety of a pre-specified 12-month interim analysis of the study.

\section{Methods}

\section{Study design}

APOLLON (NCT02924311) was a prospective, multicentre, observational cohort study of patients with DME conducted in French private and public ophthalmological clinics and practices between September 2016 and July 2019. Data were collected during clinical visits at baseline; after each IVT-AFL treatment in the first 5 months; and at 6, 12, and 24 months post-treatment start in treatment-naïve patients and previously treated patients (previously treated with an anti-VEGF agent (other than IVT-AFL), laser, or steroids at IVT-AFL treatment start).

This study was conducted in accordance with the International Conference on Harmonisation guidelines for Good Clinical Practice and the ethical principles of the 1964 Declaration of Helsinki and its later amendments or comparable ethical standards. The study protocol and informed consent forms were reviewed and approved by the French Consultative Committee on the Processing of Information in Health Research and by the French National Medical Council prior to any patient being enrolled into the study.

\section{Endpoints}

The primary endpoint was change from baseline in bestcorrected visual acuity (BCVA) at 12 months in the treatment-naïve cohort and the previously treated cohort. Secondary endpoints included the change from baseline in BCVA in the whole population at 12 months, change in central retinal thickness (CRT) between baseline and 12-month follow-up for all cohorts, frequency of injections over 12 months, and proportion of patients with safety events.

\section{Patients}

Patients aged $\geq 18$ years with type 1 or type 2 diabetes diagnosed with baseline visual acuity $\leq 5 / 10(\leq 20 / 40)$ due to DME were included. Patients with other retinal disease who were already in treatment with IVT-AFL, taking part in an interventional study, or using any anti-VEGF therapy were excluded. To reduce selection biases, patients were recruited in a consecutive manner. Patients could withdraw from the study at any time or could be withdrawn at the discretion of the investigator or sponsor for safety, behavioural, or administrative reasons.

\section{Variables}

BCVA was recorded using Early Treatment Diabetic Retinopathy Study (ETDRS) scores or Snellen chart converted to approximate ETDRS letter scores [8].

\section{Statistical analysis}

Demographic information, medical history, and clinical characteristics were collected by treating ophthalmologists or medical staff from available medical records and at the time of follow-up. For the 2-year APOLLON study, a sample size of 385 patients was calculated to produce a two-sided $95 \%$ confidence interval with a distance from the mean to the limits equal to 1099 when the known standard deviation (SD) is 11,000 .

For the effectiveness analysis, continuous variables were presented as mean (SD) and categorical variables as numbers and percentages. The last observation carried forward method or the median of the population was used to replace missing data. All statistical calculations were performed with SAS version 9.2 or higher (SAS Institute Inc., Cary, NC, USA). The safety analysis was conducted on the safety set comprising all patients who received at least one IVT-AFL injection. Treatment-emergent adverse events (TEAEs) were summarised using the Medical Dictionary for Regulatory Activities coding system. 


\section{Results}

\section{Baseline characteristics}

Of the 402 patients with DME enrolled in the study, 374 patients were included in the full analysis set and 388 patients were included in the safety analysis (Fig. 1). Of the 147 patients who were followed for at least 12 months at the time of this analysis, $52.4 \%(n=77)$ were treatment-naïve and $47.6 \%(n=$ 70) were previously treated. Of the patients who were followed for at least 12 months, six patients terminated the study prematurely (i.e., terminated the study before $24 \pm 1$ months), five patients discontinued due to switching to another treatment, and one patient changed their treating physician. The main reasons for switching treatment were lack of efficacy $(n=2)$ and decision of the treating ophthalmologist $(n=3)$.

Baseline demographic and clinical characteristics are provided in Table 1. Overall, 55.8\% of patients were male, the mean age was 65.8 years, and the median time (quartile 1; quartile 3 ) since last treatment in the previously treated cohort was $3.1(1.5 ; 6.9)$ months. The visual and anatomic characteristics are provided in Table 1. Mean (SD) BCVA ETDRS letter score was 61.4 (14.0) and mean (SD) CRT was 448.4 (124.1) $\mu \mathrm{m}$ for the overall patient population.

\section{Visual acuity at 12 months}

Change in mean (SD) BCVA from baseline was + 7.8 (12.3) letters in the treatment-naïve cohort and +5.0 (11.3) letters in the previously treated cohort, whereas it was +6.5 (11.9) letters in the overall population (Fig. 2a). Change in mean (SD) BCVA score in the subgroup of patients with $\geq 70$ letters at baseline was $+3.6(7.4)$ for treatment-naïve patients $(n=24)$ and $+1.9(6.7)$ for previously treated patients $(n=16)$. Letter gains and losses according to treatment cohort are shown in Fig. 2 b. A greater proportion of treatment-naïve patients experienced letter gains than previously treated patients, whereas the proportion of patients experiencing letter losses was similar across all cohorts. Patients with lower BCVA letter score at baseline reported the highest change in BCVA letter scores at month 12 in both treatment cohorts compared with patients with higher BCVA letter scores at baseline (Fig. 2c).

In the treatment-naïve cohort, change in mean (SD) BCVA in patients receiving the full five initial doses $(51.9 \%, n=40)$ within the first 5 months (i.e., within $150+15$ days from the first injection) was +8.4 (13.8) letters compared with +7.2 (10.4) letters in patients who did not receive the five initial doses $(48.1 \%, n=37)$. Gains of $\geq 10$ letters were achieved by $52.5 \%(n=21)$ of patients receiving the five initial doses compared with $37.8 \%(n=14)$ who did not receive the five initial doses. Gains of $\geq 15$ letters were achieved in $35.0 \%(n=14)$ of patients receiving the five initial doses compared with $24.3 \%$ $(n=9)$ of patients who did not receive the five initial doses.

\section{Anatomic outcomes at month 12}

At month 12, mean (SD) CRT decreased from 439.0 (120.3) $\mu \mathrm{m}$ at baseline to $305.6(94.3$; total reduction -129.5$) \mu \mathrm{m}$ in treatment-naïve patients and from 459.7 (128.6) $\mu \mathrm{m}$ to 318.8 (105.0; total reduction -137.6$) \mu \mathrm{m}$ in previously treated patients. When looking at the overall population, mean (SD) CRT decreased from 448.4 (124.1) $\mu \mathrm{m}$ at baseline to 311.5 (99.1; total reduction - 133.2) $\mu \mathrm{m}$ at month 12 . Mean change in CRT over the course of 12 months and according to treatment cohort is shown in Fig. 3.

At baseline, subretinal fluid (SRF) was observed in $30.3 \%$ of treatment-naïve patients and $20.0 \%$ of previously treated patients. At month 12, the proportion of patients with SRF
Fig. 1 Patient disposition. ${ }^{\mathrm{a}} \mathrm{A}$ patient could have multiple reasons for exclusion. BCVA, best-corrected visual acuity

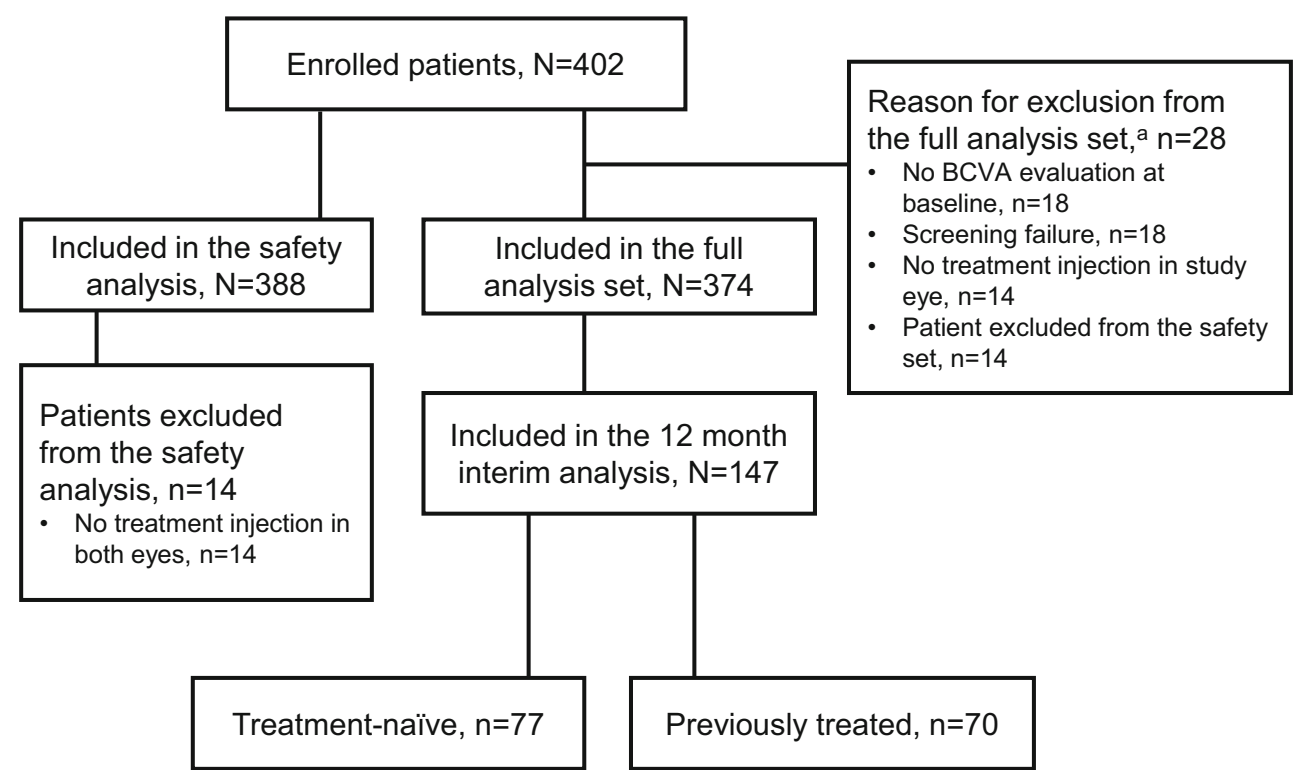


Table 1 Patient baseline characteristics

\begin{tabular}{|c|c|c|c|}
\hline & $\begin{array}{l}\text { Treatment-naïve } \\
(n=77)\end{array}$ & $\begin{array}{l}\text { Previously treated } \\
(n=70)\end{array}$ & $\begin{array}{l}\text { Overall } \\
(N=147)\end{array}$ \\
\hline Age, years & $65.2(11.2)$ & $66.5(10.6)$ & $65.8(10.9)$ \\
\hline Males $(n(\%))$ & $46(59.7)$ & $36(51.4)$ & $82(55.8)$ \\
\hline BMI $(\mathrm{kg} / \mathrm{m})$ & $28.9(6.4)$ & $30.0(5.4)$ & $29.5(5.9)$ \\
\hline $\begin{array}{l}\text { Median time since last DME treatment, months } \\
\text { (Q1-Q3) } \\
\text { Anti-VEGF agent }(n(\%)[n=47])\end{array}$ & - & $3.1(1.5-6.9)$ & - \\
\hline Ranibizumab $^{\mathrm{a}}(n(\%))$ & - & 44 (93.6) & - \\
\hline $\begin{array}{l}\text { Median ranibizumab treatment duration, } \\
\text { months }(\mathrm{Q} 1-\mathrm{Q} 3)\end{array}$ & - & $6.2(2.3-20.4)$ & - \\
\hline $\begin{array}{l}\text { Mean number of ranibizumab injections } \\
\text { received }(n=45)\end{array}$ & - & $8.8(7.5)$ & - \\
\hline Photocoagulation laser $^{\mathrm{a}}(n(\%)[n=68])$ & - & $41(60.3)$ & - \\
\hline \multicolumn{4}{|l|}{ Metabolic characteristics } \\
\hline Systolic blood pressure (mmHg) & $143.3(22.4)$ & $139.6(19.0)$ & $141.2(20.5)$ \\
\hline Diastolic blood pressure (mmHg) & $75.7(13.4)$ & $77.8(9.1)$ & $76.9(11.1)$ \\
\hline $\mathrm{HbA}_{1 \mathrm{c}}(\%)$ & $7.9(1.5)$ & $7.5(1.3)$ & $7.7(1.4)$ \\
\hline \multicolumn{4}{|l|}{ Diabetes $(n(\%))$} \\
\hline Type 1 & $12(15.6)$ & $8(11.6)$ & $20(13.7)$ \\
\hline Type 2 & $65(84.4)$ & $61(88.4)$ & $126(86.3)$ \\
\hline $\begin{array}{l}\text { Median time since DME diagnosis, months } \\
\quad(\mathrm{Q} 1-\mathrm{Q} 3)\end{array}$ & $1.0(0.3 ; 2.8)$ & $23.8(11.3 ; 41.6)$ & $\begin{array}{c}8.6(0.8 \\
28.5)\end{array}$ \\
\hline \multicolumn{4}{|l|}{ Visual and anatomic outcomes } \\
\hline BCVA, letters & $62.7(14.3)$ & $60.0(13.7)$ & $61.4(14.0)$ \\
\hline$\leq 24$ letters $(n(\%))$ & $2(2.6)$ & $2(2.9)$ & $4(2.7)$ \\
\hline 24-70 letters $(n(\%))$ & $51(66.2)$ & $52(74.3)$ & $103(70.1)$ \\
\hline$\geq 70$ letters $(n(\%))$ & $24(31.2)$ & $16(22.9)$ & $40(27.2)$ \\
\hline $\mathrm{CRT}(\mu \mathrm{m})$ & $439.0(120.3)$ & $459.7(128.6)$ & $\begin{array}{l}448.4 \\
\quad(124.1)\end{array}$ \\
\hline Subretinal fluid visible on OCT $(n(\%))$ & $23(30.3)$ & $13(20.0)$ & $36(25.5)$ \\
\hline Intraretinal fluid visible on OCT $(n(\%))$ & $72(94.7)$ & $64(95.5)$ & $136(95.1)$ \\
\hline
\end{tabular}

Data are reported as mean (SD) unless otherwise stated and are for those who received an assessment

${ }^{a}$ Patients previously treated with the indicated treatment. A patient may have received several previous treatments for DME

$B C V A$ best-corrected visual acuity, $B M I$ body mass index, $C R T$ central retinal thickness, $D M E$ diabetic macular edema, $H b A_{1 c}$ haemoglobin A1C, OCT optical coherence tomography, $Q$ quartile, $S D$ standard deviation, $V E G F$ anti-vascular endothelial growth factor decreased to $5.5 \%$ in treatment-naïve and $4.7 \%$ in previously treated patients. Baseline IRF was observed in $\sim 95.0 \%$ of patients in both treatment cohorts. At month 12, the proportion of patients with IRF decreased to $67.1 \%$ of treatment-naïve and $70.3 \%$ of previously treated patients.

\section{Number of injections at month 12}

Forty $(51.9 \%)$ treatment-naïve patients, 22 (31.4\%) previously treated patients, and 62 patients $(42.2 \%)$ overall received the five initial doses of IVT-AFL. Mean (SD) number of IVTAFL injections was 7.6 (2.5) in treatment-naïve patients, 7.6 (2.3) in previously treated patients, and $7.6(2.4)$ in the overall population. A total of $40(51.9 \%)$ treatment-naïve patients, 36
$(51.4 \%)$ previously treated patients, and $76(51.7 \%)$ patients in the overall population received $\leq 8$ injections. The number of injections based on BCVA score at baseline is shown in Fig. 4. Mean number of injections at month 12 in the treatment-naïve cohort increased with increasing baseline BCVA letter scores. In the previously treated cohort, the mean (SD) number of injections was higher in patients with $<24$ BCVA letter score at baseline compared with patients with $>24$ BCVA letter score at baseline.

\section{Safety analysis at month 12}

Over the $12-$ month study period, $54.1 \%(n=210)$ of patients reported ocular TEAEs and $34.8 \%(n=135)$ of patients 


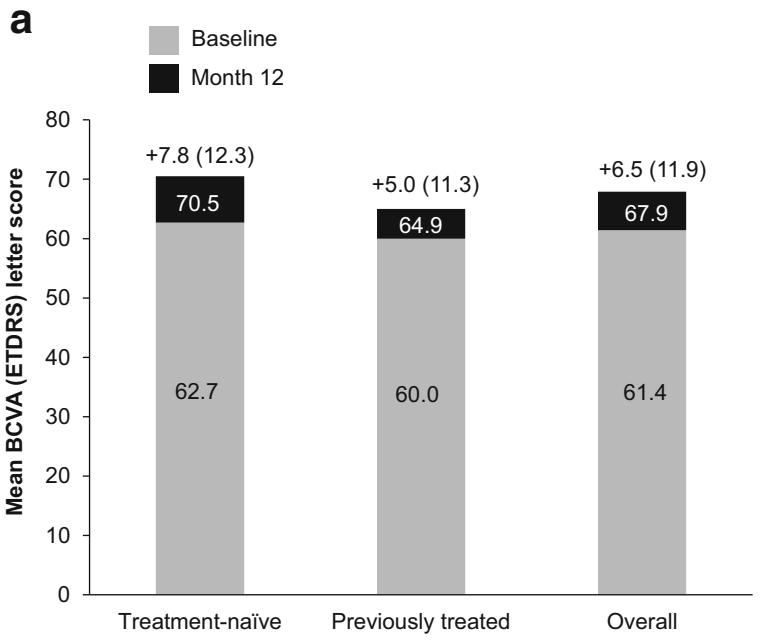

b
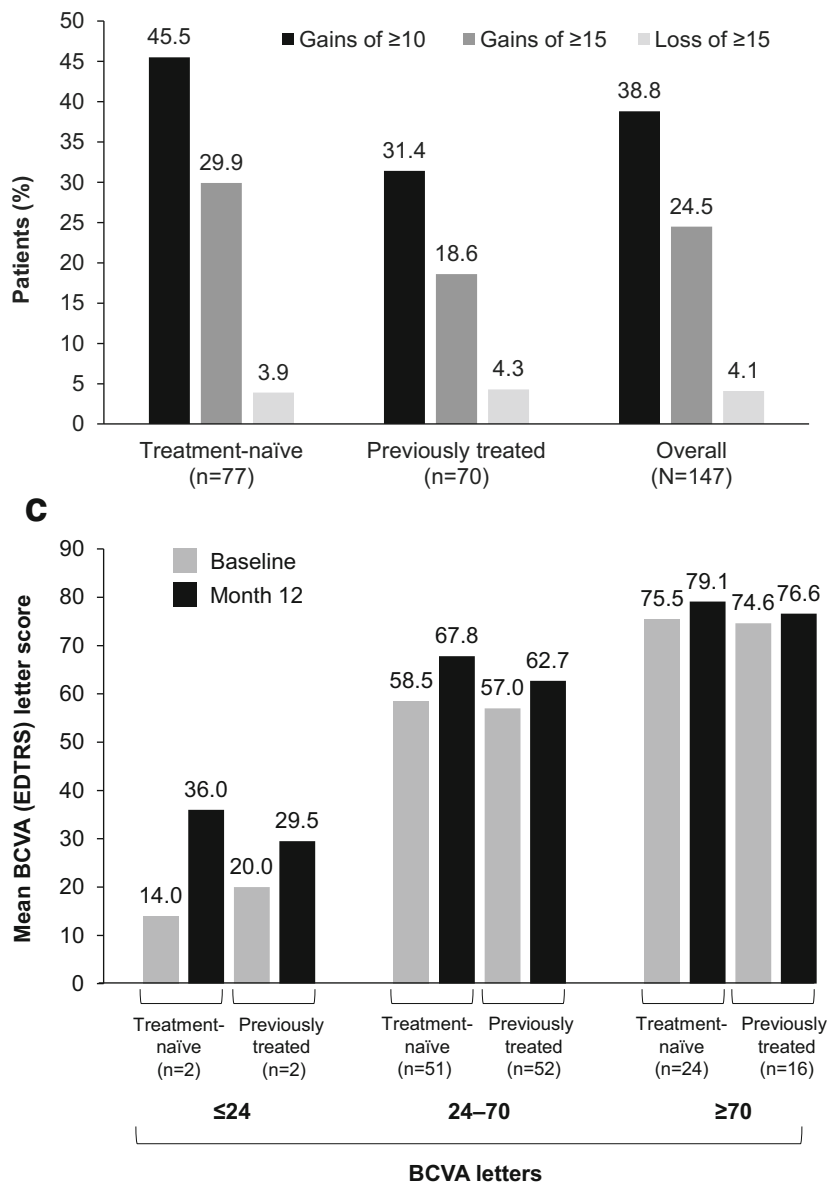

Fig. 2 a Visual acuity gains from baseline to month 12. Numbers on top of columns indicate mean change in BCVA letter score (SD) from baseline to month 12. b Letter gains and losses based on treatment cohort. $\mathbf{c}$ Change in mean BCVA letter score from baseline to month 12 based on treatment cohort and baseline BCVA letter score. BCVA, best-corrected visual acuity; ETDRS, Early Treatment Diabetic Retinopathy Study; SD, standard deviation

reported ocular TEAEs that were deemed to be related to IVTAFL treatment. The most commonly $(\geq 2.0 \%)$ observed ocular TEAEs were cataract $(4.4 \%, n=17)$, diabetic retinal edema (recurrence or aggravation, $3.1 \%, n=12$ ), visual acuity reduced $(2.8 \%, n=11)$, and macular edema (recurrence, $2.3 \%, n=9$ ). Two cases of endophthalmitis were also reported. A list of safety events is reported in Table 2. Treatment withdrawal due to ocular TEAEs occurred in $0.8 \%(n=3)$ of patients. Serious ocular TEAEs occurred in $2.8 \%(n=11)$ of patients. One serious ocular TEAE (vitreous detachment) in one patient was deemed to be related to IVT-AFL treatment. Three deaths $(0.8 \%)$ occurred and were assessed to be not related to study drug.

\section{Discussion}

This 12-month interim analysis of the APOLLON study showed that IVT-AFL injections were associated with functional and anatomic benefits in French private and public clinical practice, which was consistent with results observed in randomised controlled trials (VIVID, mean change in BCVA score at 12 months was +10.7 letters) and other real-world studies (Moorfields' realworld study, mean change in BCVA score at 12 months was +9.9 letters) $[7,9]$. Visual gains observed in the APOLLON study were particularly meaningful given that more than $60 \%$ of patients had baseline BCVA letter score $\geq 60$, and eyes with better baseline vision have less potential to gain letters than eyes with poorer baseline vision [10].

In this study, treatment-naïve patients achieved better visual outcomes than previously treated patients, even though mean baseline BCVA letter scores were similar between the two treatment cohorts. One possibility for the outcomes of the current interim analysis is that treatment-naïve patients received earlier and more effective care compared with previously treated patients, and did not have other conditions, such as chronic macular edema. Moreover, patients who were refractory to previous treatments were also included in the previously treated cohort, and this patient subgroup might have had a lower response to IVT-AFL treatment than non-refractory previously treated patients. Further investigations are required to evaluate if the switch to IVT-AFL was beneficial in this patient subgroup; however, this is beyond the scope of the present analysis.

In our study, both patient cohorts experienced improvements in anatomic outcomes and a decline in both SRF and IRF following IVT-AFL treatment. Previous studies found that the presence of SRF was associated with likelihood of treatment response [11]; however, if left untreated, SRF may be detrimental in the long term, whereas IRF is associated with poor visual acuity and is difficult to treat, suggesting that the improvements 
Fig. 3 Mean CRT change across 12 months and according to treatment cohort. CRT, central retinal thickness

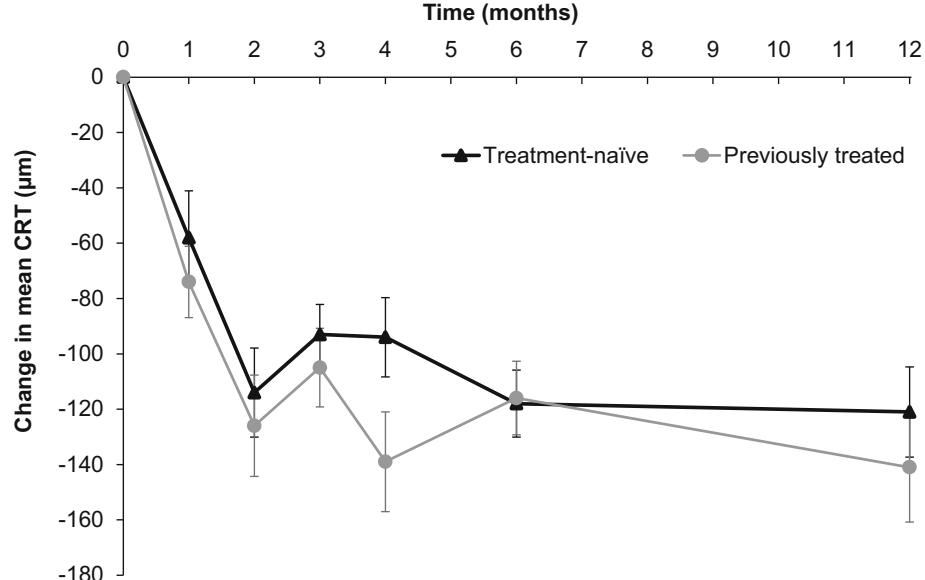

Treatment-naïve, $n$ Previously treated, $\mathrm{n}$ $\begin{array}{rrrr}46 & 54 & 110 & 73 \\ 57 & 63 & 98 & 64\end{array}$ 112 75

observed in APOLLON may provide additional benefits hereafter. However, an important proportion of patients in both treatment cohorts had residual IRF at month 12 despite receiving several intra- and inter-class treatments, which may correspond to time of recurrence in some patients under different treatment regimens, and highlights the current challenges faced by ophthalmologists in providing effective care to patients with DME.

Treatment of DME with IVT-AFL is indicated to be initiated with five consecutive monthly injections, followed by one injection every $\sim 2$ months [12]. Adoption of a regimen that includes the five initial IVT-AFL doses has been beneficial in improving visual outcomes in patients with DME [13]. In the patient cohort of the present analysis, a greater proportion of treatment-naïve patients than of previously treated patients received the five initial IVT-AFL doses and adoption of this regimen may have contributed to greater

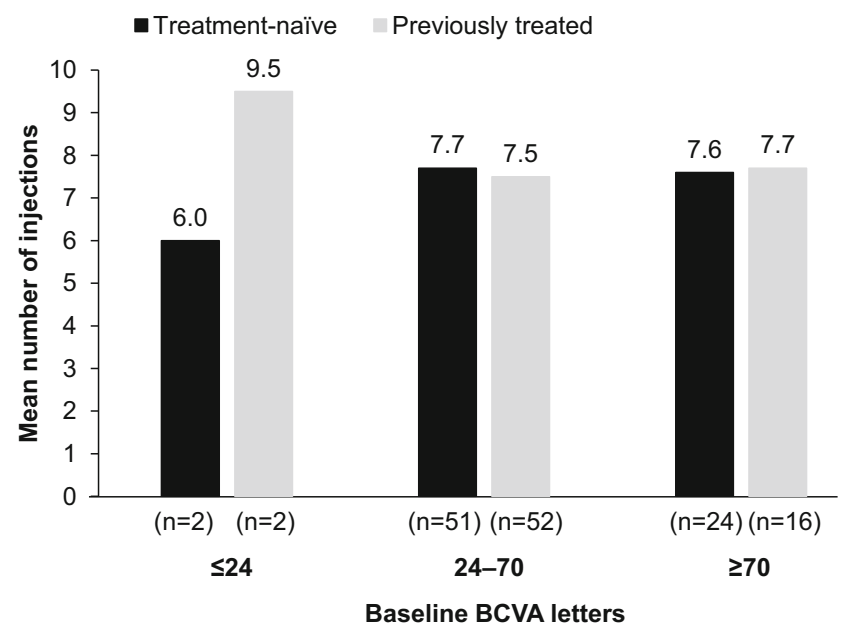

Fig. 4 Number of injections received per BCVA letter score at baseline and treatment cohort over 12 months. BCVA, best-corrected visual acuity improvements in visual outcomes. Previously treated patients might have missed the five initial doses based on the physician's decision to switch to IVT-AFL from other anti-VEGF agents without starting the indicated initiation protocol. Despite this difference, the total mean number of injections was similar between treatment cohorts, although previously treated patients with

Table 2 Summary of main safety events (safety analysis set)

\begin{tabular}{lc}
\hline & $N=388(n(\%))$ \\
\hline Most common AEs (> 5.0\%) & \\
Inappropriate schedule of drug administration & $174(44.8)$ \\
Product use issue & $75(19.3)$ \\
Off label use & $24(6.2)$ \\
Any ocular TEAE & $210(54.1)$ \\
Any ocular TEAE (> 1.0\%) & \\
Cataract & $17(4.4)$ \\
Diabetic retinal edema & $12(3.1)$ \\
Visual acuity reduced & $11(2.8)$ \\
Macular edema & $9(2.3)$ \\
Vitreous floaters & $7(1.8)$ \\
Ocular hypertension & $5(1.3)$ \\
Any treatment-related ocular TEAE & $135(34.8)$ \\
Any serious ocular TEAE & $11(2.8)$ \\
Any serious treatment-related ocular TEAE & $1(0.3)$ \\
Any non-ocular TEAE & $178(45.9)$ \\
Any ocular TEAE leading to discontinuation & $3(0.8)$ \\
Any treatment-related non-ocular TEAE & $110(28.4)$ \\
Any serious non-ocular TEAE & $49(12.6)$ \\
Any serious treatment-related non-ocular TEAE & $2(0.5)$ \\
Any non-ocular TEAE leading to discontinuation & $6(1.5)$ \\
\hline
\end{tabular}

There were no serious AEs $>2 \%$

$A E$ adverse event, TEAE treatment-emergent adverse event 
lower BCVA letter scores at baseline tended to receive more injections than treatment-naïve patients in the corresponding BCVA letter score subgroup. When comparing real-world with randomised controlled trials, the overall number of injections in APOLLON was lower than that reported in VIVID (7.6 vs 8.7 , respectively) [7]; however, a fixed-dosing regimen was adopted in VIVID, whereas the adopted IVT-AFL regimens in APOLLON might have been more variable and interpretation of these results warrants caution. In terms of safety, the incidence of adverse events in the APOLLON study was consistent with the known safety profile of anti-VEGF agents, with cataract and diabetic retinal edema being the most common ocular events.

This study had some limitations as observational studies are subject to recruitment and practice biases (visual acuity measurements are not standardised). Other limitations include its small size and the fact that these findings were not adjusted for confounders, such as age and disease severity. Strengths of this study include the prospective design and that patient cohorts were well defined.

In conclusion, this interim analysis of the APOLLON study showed that IVT-AFL for the treatment of DME was associated with improved functional and anatomic outcomes. In addition, treatment-naïve patients showed a trend toward better visual and anatomic improvements than those observed in previously treated patients, suggesting that early and effective treatment may prevent irreversible vision loss.

Acknowledgements Medical writing support was provided by Sabrina Giavara, PhD (ApotheCom, UK) and funded by Bayer Consumer Care AG, Pharmaceuticals, Switzerland.

Author contribution All authors were responsible for and/or involved in provision of patients/data acquisition, data analysis, data review, and interpretation. All authors reviewed the manuscript and approved the final version for submission.

Funding information This study was funded by Bayer SAS, France. Bayer participated in the design of the study; analysis and interpretation of the data; and development of the manuscript. Bayer was responsible for the conduct of the study and oversight of the collection and management of data.

\section{Compliance with ethical standards}

Conflict of interest JFK has been a consultant for Allergan, Bayer, Beaver-Visitec, Horus Pharma, Krystal Biotech, Chengdu Kanghong, Nano Retina, Novartis, Novo Nordisk, Oxurion, Roche, Théa, and Zeiss; VD has received consulting fees from Bayer, Novartis, Théa, and Horus Pharma; $\mathrm{CF}$ and $\mathrm{CD}$ have received consulting fees from Allergan, Bayer, and Novartis; RT has received consulting fees from Alcon, Bausch \& Lomb, FCI Ophthalmics, Moria, Optovue, Zeiss, Alimera, Allergan, Bayer, Genentech, Novartis, Roche, and Théa; AGA has received consulting fees from Allergan, Bayer, Novartis, and Optos; LK has been a consultant for AbbVie, Alcon, Allergan, Bayer, Krystal Biotech,
Novartis, Regeneron, and Théa; and PM has received consulting fees from Bayer, Novartis, Allergan, Horus Pharma, Sanofi, and Merck Sharp \& Dohme.

Ethical approval All procedures performed involving human participants were in accordance with the ethical standards of the (place name of institution and/or national research committee) and with the 1964 Helsinki declaration and its later amendments or comparable ethical standards.

Informed consent Informed consent was obtained from all individual participants included in the study.

Open Access This article is licensed under a Creative Commons Attribution 4.0 International License, which permits use, sharing, adaptation, distribution and reproduction in any medium or format, as long as you give appropriate credit to the original author(s) and the source, provide a link to the Creative Commons licence, and indicate if changes were made. The images or other third party material in this article are included in the article's Creative Commons licence, unless indicated otherwise in a credit line to the material. If material is not included in the article's Creative Commons licence and your intended use is not permitted by statutory regulation or exceeds the permitted use, you will need to obtain permission directly from the copyright holder. To view a copy of this licence, visit http://creativecommons.org/licenses/by/4.0/.

\section{References}

1. Schmidt-Erfurth U, Garcia-Arumi J, Bandello F, Berg K, Chakravarthy U, Gerendas BS, Jonas J, Larsen M, Tadayoni R, Loewenstein A (2017) Guidelines for the management of diabetic macular edema by the European Society of Retina Specialists (EURETINA). Ophthalmologica. 237:185-222. https://doi.org/ $10.1159 / 000458539$

2. Lee R, Wong TY, Sabanayagam C (2015) Epidemiology of diabetic retinopathy, diabetic macular edema and related vision loss. Eye Vis (Lond). 2:17. doi: https://doi.org/10.1186/s40662-015-0026-2. eCollection 2015. doi: https://doi.org/10.1186/s40662-015-0026-2

3. World Health Organization (2018) Diabetes. https://www.who.int/ news-room/fact-sheets/detail/diabetes. Accessed 22 October 2019

4. Klein R, Klein BE, Moss SE, Cruickshanks KJ (1995) The Wisconsin epidemiologic study of diabetic retinopathy. XV. The long-term incidence of macular edema. Ophthalmology. 102:716. doi: https://doi.org/10.1016/s0161-6420(95)31052-4

5. Kent D, Vinores SA, Campochiaro PA (2000) Macular oedema: the role of soluble mediators. Br J Ophthalmol 84:542-545. https://doi. org/10.1136/bjo.84.5.542

6. Selim KM, Sahan D, Muhittin T, Osman C, Mustafa O (2010) Increased levels of vascular endothelial growth factor in the aqueous humor of patients with diabetic retinopathy. Indian J Ophthalmol 58:375-379. https://doi.org/10.4103/0301-4738. 67042

7. Korobelnik JF, Do DV, Schmidt-Erfurth U, Boyer DS, Holz FG, Heier JS, Midena E, Kaiser PK, Terasaki H, Marcus DM, Nguyen QD, Jaffe GJ, Slakter JS, Simader C, Soo Y, Schmelter T, Yancopoulos GD, Stahl N, Vitti R, Berliner AJ, Zeitz O, Metzig C, Brown DM (2014) Intravitreal aflibercept for diabetic macular edema. Ophthalmology. 121:2247-2254. https://doi.org/10.1016/j. ophtha.2014.05.006

8. Gregori NZ, Feuer W, Rosenfeld PJ (2010) Novel method for analyzing Snellen visual acuity measurements. Retina. 30:1046-1050. https://doi.org/10.1097/IAE.0b013e3181d87e04 
9. Lukic M, Williams G, Shalchi Z, Sim D, Patel PJ, Keane PA, Hykin PG, Sivaprasad S, Menon D, Bruynseels A, Hamilton RD, Rajendram R (2019) Intravitreal aflibercept for diabetic macular oedema: Moorfields' real-world 12-month visual acuity and anatomical outcomes. Eur J Ophthalmol 1120672119833270. https:// doi.org/10.1177/1120672119833270

10. Boyer DS, Antoszyk AN, Awh CC, Bhisitkul RB, Shapiro H, Acharya NR, Group MS (2007) Subgroup analysis of the MARINA study of ranibizumab in neovascular age-related macular degeneration. Ophthalmology. 114:246-252. doi: https://doi.org/ 10.1016/j.ophtha.2006.10.045

11. Sophie R, Lu N, Campochiaro PA (2015) Predictors of functional and anatomic outcomes in patients with diabetic macular edema treated with ranibizumab. Ophthalmology. 122:1395-1401. https://doi.org/10.1016/j.ophtha.2015.02.036

12. International Diabetes Federation (2017) IDF Diabetes Atlas. https://diabetesatlas.org/resources/2017-atlas.html.

13. Ziemssen F, Schlottman PG, Lim JI, Agostini H, Lang GE, Bandello F (2016) Initiation of intravitreal aflibercept injection treatment in patients with diabetic macular edema: a review of
VIVID-DME and VISTA-DME data. Int J Retina Vitreous 2:16. https://doi.org/10.1186/s40942-016-0041-z

Prior presentations - Annual Meeting of The Association for Research in Vision and Ophthalmology (ARVO); 28 April-2 May 2019; Vancouver, Canada

- Congress of the French Society of Ophthalmology (SFO); 11-14 May 2019; Paris, France

- MaculArt meeting; 23-25 June 2019; Paris, France

- Congress of the European Society of Retina Specialists (EURETINA); 5-8 September 2019; Paris, France

Publisher's note Springer Nature remains neutral with regard to jurisdictional claims in published maps and institutional affiliations. 